\title{
Inhibition of Fungal Spore Adhesion by Zosteric Acid as the Basis for a Novel, Nontoxic Crop Protection Technology
}

\author{
Michele S. Stanley, Maureen E. Callow, Ruth Perry, Randall S. Alberte, Robert Smith, and James A. Callow
}

First, second, third, and sixth authors: School of Biosciences, The University of Birmingham, Birmingham B15 2TT, UK; and fourth and fifth authors: Edson Mitchell Laboratory, PhycoGen Inc., 360 US Route 1, Falmouth, ME 04105.

Current addresses of R. S. Alberte and R. Smith: Affynis Biosciences Inc., 418 Middle Road, Falmouth, ME 04105.

Accepted for publication 30 November 2001.

\begin{abstract}
Stanley, M. S., Callow, M. E., Perry, R., Alberte, R. S., Smith, R., and Callow, J. A. 2002. Inhibition of fungal spore adhesion by zosteric acid as the basis for a novel, nontoxic crop protection technology. Phytopathology 92:378-383.

To explore the potential for nontoxic crop protection technologies based on the inhibition of fungal spore adhesion, we have tested the effect of synthetic zosteric acid ( $p$-(sulfo-oxy) cinnamic acid), a naturally occurring phenolic acid in eelgrass (Zostera marina L.) plants, on spore

muthianum. We have shown that zosteric acid inhibits spore adhesion to model and host leaf surfaces and that any attached spores fail to develop appressoria, and consequently do not infect leaf cells. Low concentrations of zosteric acid that are effective in inhibiting adhesion are not toxic to either fungus or to the host. The inhibition of spore adhesion in the rice blast pathogen is fully reversible. On plants, zosteric acid reduced (rice) or delayed (bean) lesion development. These results suggest that there is potential for novel and environmentally benign crop protection technologies based on manipulating adhesion.
\end{abstract} adhesion and infection in two pathosystems: rice blast caused by Magnaporthe grisea and bean anthracnose caused by Colletotrichum linde-

The development of resistance to common fungicides and increasing restrictions on the use of toxic materials in the environment has given impetus to the search for novel plant protectants that interfere with fungal pathogenicity factors, some of which are expressed during the prepenetration phase of infection. Adhesion of fungal spores to the host surface via extracellular matrices (ECMs) is regarded as an essential first step in the infection of host cells $(1,3,5,12,15)$ and the adhesion factors (adhesins) involved are thus logical targets for intervention. For example, in the extensively researched rice blast fungus, Magnaporthe grisea, hydration of conidia (asexual spores) results in the release from the spore tip of an adhesive mucilage with a great affinity for highly hydrophobic materials such as those presented by the rice leaf cuticle (7). Without adhesion, $M$. grisea conidia rapidly lose viability (17), but once attached they germinate within $1 \mathrm{~h}$ to form a germ tube. Adhesion of germ tubes to the leaf surface via ECMs is important in the perception of external signals indicating hardness and hydrophobicity that trigger a complex differentiation process resulting in the cessation of tip growth and the formation of an appressorium, a melanized infection structure. Adhesion of the appressorium to the leaf surface via ECMs is also critical in forming an effective base from which the subsequent penetration of the turgid leaf cell can take place (9). Many other directly penetrating fungi have a broadly similar infection strategy, and the range of adhesion mechanisms and the nature of the protein/glycoprotein ECMs or adhesins used by fungi have been extensively reviewed $(1,5)$.

An understanding of prepenetration mechanisms of adhesion may suggest novel methods to control plant disease, and some compounds that control rice blast inhibit appressorial attachment (11). To our knowledge, however, agents have not yet been developed that directly interfere with spore adhesion. Zosteric acid ( $p$-(sulfo-

Corresponding author: J. A. Callow; E-mail address: j.a.callow@bham.ac.uk

Publication no. P-2002-0130-02R

(C) 2002 The American Phytopathological Society
Additional keywords: adhesins, anti-adhesion technology. oxy) cinnamic acid) is a naturally occurring sulfated phenolic acid in the eelgrass Zostera marina (19). The compound inhibits the attachment of marine bacteria and barnacle larvae (19) and the spores of the green alga Enteromorpha (2) at nontoxic concentrations. This broad spectrum of nontoxic, anti-adhesive effects has prompted an assessment of the potential of zosteric acid to inhibit adhesion in other contexts where adhesion in aqueous environments is critical, in this case the dew droplets where most species of plant pathogenic fungi initiate the infection process. The two Ascomycete fungi chosen for this study were the rice blast pathogen $M$. grisea and the bean anthracnose pathogen Colletotrichum lindemuthianum. Both species are common models for mechanistic studies on spore adhesion and pathogen molecular genetics, but differ in the adhesion mechanism used by ungerminated spores. In the case of $M$. grisea, an adhesive glycoprotein is contained within a specific compartment at the tip of the spore and is discharged on hydration (7), whereas in C. lindemuthianum and other Colletotrichum spp., the initial adhesive is part of a fibrillar spore coating (10).

Here we report that at nontoxic concentrations, zosteric acid reduces adhesion of spores of these two phytopathogenic fungi to model (polystyrene) and natural (leaf) surfaces. Furthermore, spores that do adhere show a reduced ability to initiate subsequent infection structures. Consequently, disease symptom development is reduced. The results suggest considerable potential for environmentally benign strategies for the control of plant disease based on anti-adhesion compounds.

\section{MATERIALS AND METHODS}

Zosteric acid. Technical grade zosteric acid synthesized by sulfonation of coumaric acid using triethylamine sulfur complex (Fluorochem, Azusa, CA) was used for all investigations. The resultant product was $>90 \%$ zosteric acid ( $p$-(sulfo-oxy) cinnamic acid) with $<10 \%$ sodium chloride and 1 to $2 \%$ of diesters of zosteric acid and zosteric acid/coumaric acid (composition in percent weight). 
Fungal pathogens. C. lindemuthianum (Sacc. \& Magnus) Lams.-Scrib. race $\kappa$ (Long Ashton Research Station Culture Collection no. 137) was grown on medium described by Mathur et al. (14) and cultured at $17^{\circ} \mathrm{C}$ under continuous illumination with black fluorescent lights (Philips TDL/36W) as described by Pain et al. (16). Conidia from 7-day-old cultures were collected as described by Hughes et al. (10) and resuspended in distilled water. M. grisea strain Guy 11 was grown on a complete medium (18) under a $12 \mathrm{~h} \mathrm{light/dark}$ cycle at $25^{\circ} \mathrm{C}$. Conidia harvested from 10-day-old cultures in $0.2 \%$ (wt/vol) gelatin, as described by Hamer et al. (7), were washed by centrifugation $(2,500 \mathrm{rpm}$ for $10 \mathrm{~min}$, MSE/Sanyo 3,000 centrifuge) and resuspended in $1 \mathrm{mM}$ sodium phosphate buffer, $\mathrm{pH}$ 7.0.

Adhesion assays on polystyrene. The polystyrene dish assay for both fungi used a modification of the general method described in Hughes et al. (10). Tests of the effect of zosteric acid on spore adhesion were typically carried out unbuffered and in distilled water ( $\mathrm{pH} 7.5)$. Experiments were conducted with low concentrations $(0.01 \mathrm{M})$ of HEPES ( $N$-2-hydroxyethylpiperazine$N^{\prime}$-2-ethanesulfonic acid) buffer at $\mathrm{pH} 7.2$, but this molarity provided little buffering capacity and higher buffer concentrations could not be used because they inhibited spore adhesion. For C. lindemuthianum, spore preparations from 7-day-old cultures $\left(4 \times 10^{5}\right.$ spores $\left.\mathrm{ml}^{-1}\right)$ were mixed with an equal volume of double-strength test compound and incubated at room temperature for $15 \mathrm{~min}$. A single droplet $(100 \mu \mathrm{l})$ of treated spores was applied to each of three replicate polystyrene dishes (35-mm diameter, Falcon 3001, Becton Dickinson, Plymouth, UK) and incubated for $30 \mathrm{~min}$ at room temperature. The same method was used for $M$. grisea, except that spore preparations were made from 10-dayold cultures $\left(4 \times 10^{5}\right.$ spores $\left.\mathrm{ml}^{-1}\right)$ and dishes were incubated for $1 \mathrm{~h}$ at room temperature. After incubation, five images were taken of each droplet under a $\times 4$ objective using Analysis image capture (Soft Imaging Systems, Munster, Germany) attached to a light microscope (Olympus BH-2; Olympus Optical Co., Tokyo, Japan) with a video camera (typical spore preparations gave 60 to 70 spores per field of view). After adding $3 \mathrm{ml}$ of distilled water, the dishes were agitated on a reciprocating shaker (Heidolph Titramax 100, Schwabach, Germany) for $20 \mathrm{~s}$ at $1,000 \mathrm{rpm}$, and another set of five images was taken. The number of spores in each image was counted with image analysis software (KS300; version 3.0, Carl Zeiss, Welwyn Garden City, UK). Percentage adhesion was calculated by dividing the number of spores remaining after agitation by the number before agitation. Spores were also treated with $p$-coumaric acid (Sigma, Poole, Dorset, UK) at $0,0.01,0.1$, and $1 \%(\mathrm{wt} / \mathrm{vol})$ in distilled water adjusted to $\mathrm{pH} 7.5$ with $\mathrm{NaOH}$, yielding the sodium salt of the phenolic acid.

Leaf surface adhesion assays. Segments (6 cm long) of 21-dayold rice leaves were attached to glass slides (one segment per slide) with double-sided sticky tape. Equal volumes of spores and unbuffered zosteric acid solution ( $\mathrm{pH} 7.5$ at 1\%, wt/vol) at different concentrations were mixed together to give a final concentration of $2 \times 10^{4}$ spores $\mathrm{ml}^{-1}$ and Tween 80 was added to a final concentration of $0.025 \%(\mathrm{vol} / \mathrm{vol})$. Ten replicate droplets $(20 \mu \mathrm{l})$ of spore solution were applied to each leaf segment, which were then incubated in individual 9-cm-diameter petri dishes (Sterilin) containing dampened filter paper for $1 \mathrm{~h}$ at room temperature. The spores were stained by immersing the leaf segments in a saturated solution of the fluorescent brightener Calcofluor White M2R (Sigma) for $5 \mathrm{~min}$, washed three times by flooding each dish with distilled water, and examined under a UV epifluorescence microscope (Axioplan; Carl Zeiss). The number of adhered spores was counted in three random fields of view for each of the 10 replicate droplets on each leaf segment. The number of spores adhering for each treatment was expressed as the number of spores per square millimeter of leaf surface. The experiment was repeated twice with consistent results.
Spore adhesion of $C$. lindemuthianum to bean leaves was carried out in a similar way to that for $M$. grisea, except that 7-mm-diameter leaf disks were cut from 18-day-old bean (Phaseolus vulgaris cv. Kievetsboon Koekoek) leaves. The final concentration of spores was $1 \times 10^{5}$ spores $\mathrm{ml}^{-1}$, and 10 replicate leaf disks were used for each treatment with a $100-\mu l$ droplet of the treated spores added to each disk. After 2.5-h incubation, the leaf disks were stained and washed and spores were counted as for $M$. grisea. This experiment was repeated with similar results.

Germination and infection structure formation. To assess the influence of zosteric acid on germination and appressorium formation in $M$. grisea, spore incubations were set up on polystyrene petri dishes as described for the adhesion assays. The proportion of spores that had germinated and formed appressoria was assessed by direct microscopic counts after $16 \mathrm{~h}$ of incubation. In the case of $C$. lindemuthianum, germination, appressorium, and infection vesicle formation were assessed by inoculating bean leaves as described for the plant protection experiments. After 2 days, epidermal strips were taken from the adaxial leaf surface, stained in lactophenol-cotton blue, and examined under the microscope. Counts were made of total spores, germinated spores, appressoria, and infection vesicles inside epidermal cells, in 10 random fields of view on each of three replicate peels.

Protection experiments. Two types of protection assay were carried out on rice plants. For droplet inoculation assays, rice seeds were sown down the short axis of a seed tray $(22 \times 35 \mathrm{~cm})$, in John Innes No. 2 compost and grown in a Conviron controlled environment chamber at $25^{\circ} \mathrm{C}$, with a 16 -h photoperiod and a photon flux density of $100 \mu \mathrm{mol} \mathrm{m} \mathrm{m}^{-2} \mathrm{~s}^{-1}$. After 21 days, plants were thinned out to eight per tray and the second leaf of each seedling was gently taped down to a glass plate placed on the surface of the compost. The horizontal leaf surface was inoculated with a $10-\mu l$ droplet of spores of $M$. grisea $\left(1 \times 10^{5}\right.$ spores $\left.\mathrm{ml}^{-1}\right)$ that had been mixed with an equal volume of double-strength test compound (unbuffered). The tray was incubated within a Perspex canopy to increase the relative humidity. Droplets remained intact for $24 \mathrm{~h}$ under these conditions. Lesions were examined after 72 to $96 \mathrm{~h}$. All inoculations were repeated on duplicate leaves within the same tray, and the experiment was repeated twice with consistent results.

In the second type of protection experiment, 3-week-old glasshouse-grown rice plants (eight plants per $5-\mathrm{cm}$ pot, three pots per treatment) were sprayed with spore suspensions. Plants were presprayed with test compound, mixed with $0.015 \%$ ( $\mathrm{vol} / \mathrm{vol}$ ) of the nonionic surfactant Agral (alky phenol ethylene oxide; Zeneca) as a wetting agent, left for $24 \mathrm{~h}$, and sprayed with $5 \times 10^{5}$ spores $\mathrm{ml}^{-1}$. The pots in each treatment were collectively covered with polycarbonate bell propagators to increase the humidity for 2 days. Although lesions developed on all leaves that were exposed to the spores, for consistency, lesion counts were made on leaves of the same developmental age (the second oldest leaf) after 3 days. The experiment was repeated twice with similar results.

For the bean protection experiments, 18-day-old glasshousegrown bean plants (Phaseolus vulgaris cv. Kievitsboon Koekoek, one plant per $2.5-\mathrm{cm}$ pot, five pots per treatment) were first sprayed with unbuffered zosteric acid, allowed to dry for 2 to $3 \mathrm{~h}$, and sprayed with $1 \times 10^{6} \mathrm{C}$. lindemuthianum spores $\mathrm{ml}^{-1}$. Each plant was placed inside a plastic bag for 2 days to increase the humidity and examined for infection after 5 days. Lesion area as a proportion of total leaf area was assessed for primary unifoliate leaves by weighing appropriate areas of digitally scanned images. The entire experiment was repeated with similar results.

Fungal growth in liquid culture. The effects of zosteric acid on mycelial growth of both $M$. grisea and C. lindemuthianum were determined in stationary liquid culture. M. grisea were grown in flasks containing $100 \mathrm{ml}$ of complete medium (18) supplemented with zosteric acid at $0,0.1,1$, and $2 \%$ (wt/vol) with three replicate flasks for each treatment. Each flask was inocu- 
lated with six mycelium disks (1-cm diameter) taken from the leading edge of 10-day-old $M$. grisea cultures. The flasks were incubated at $25^{\circ} \mathrm{C}$ with a $12 \mathrm{~h} \mathrm{light/dark} \mathrm{cycle.} \mathrm{C.} \mathrm{lindemuthianum}$ was tested in the same way but using Colletotrichum medium (14) and incubation at $17^{\circ} \mathrm{C}$. After 7 days growth, mycelial mats were filtered onto predried, preweighed Whatman No. 1 filter paper, and dried to constant weight. The experiment was repeated with consistent results.

Experimental design and analysis of data. Although results of individual experiments are presented, all were repeated several times. Batch-to-batch variation in spore adhesive properties made it impossible to pool data from different experiments for statistical analysis, but although the absolute magnitude of some of the effects varied between experiments, the general trends observed were always the same. All values are represented in figures and tables as means $\pm 95 \%$ confidence limits, and percentage values were subjected to arcsine transformation.

\section{RESULTS}

The adhesion assay on polystyrene measures the number of spores attached in representative fields of view, before and after exposure to a detachment force. This distinguishes spores that are firmly adhered from those settled on, but unattached to the surface, and in control treatments, the level of adhesion approached $100 \%$ of the settled spores. Zosteric acid inhibited the adhesion of spores of both species in a concentration-dependent manner, statistically significant reductions being achieved at concentrations as low as $0.01 \%$ (wt/vol) (Fig. 1). The control nonsulfoxy phenolic acid, $p$-coumaric acid, did not inhibit spore adhesion to polystyrene at the concentrations tested.

Although zosteric acid inhibited spore adhesion to polystyrene, the ability of spores to germinate was unimpaired at 0.01 to $0.1 \%$ (wt/vol) zosteric acid, suggesting that the compound was not toxic

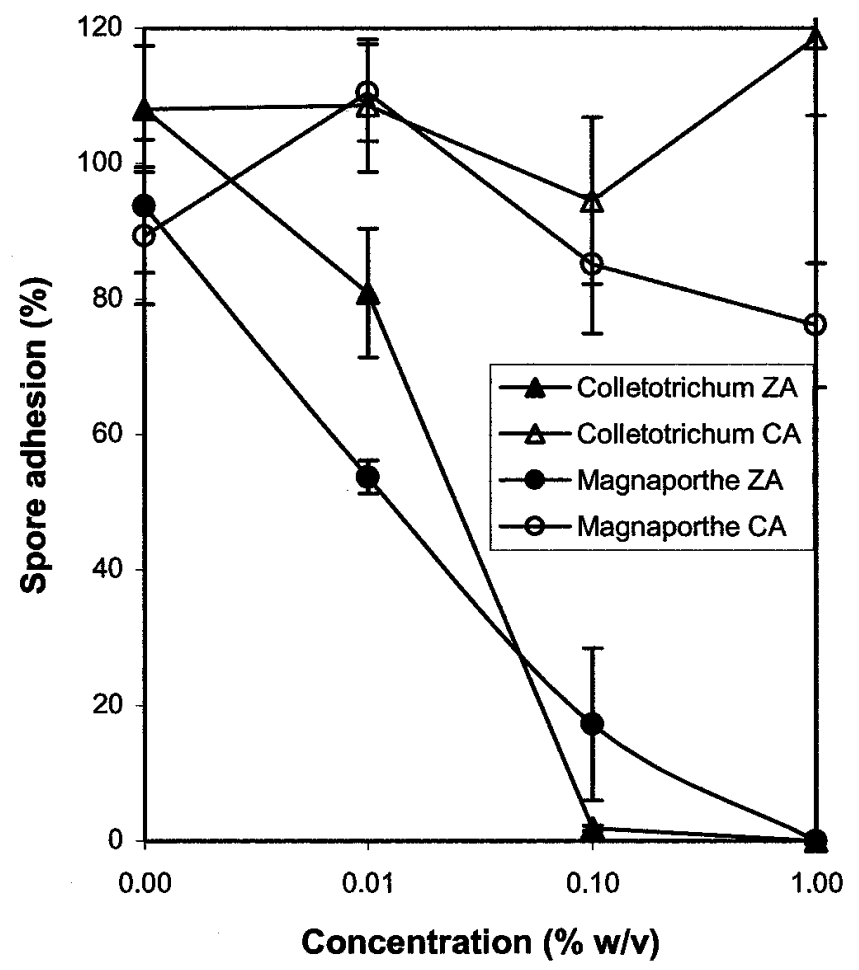

Fig. 1. Adhesion of spores of Colletotrichum lindemuthianum and Magnaporthe grisea to polystyrene in the presence of zosteric acid (ZA) and $p$ coumaric acid (CA). Percentage adhesion is determined as the number of spores remaining firmly attached to the surface after a washing treatment as a proportion of those originally present. The $95 \%$ confidence limits were plotted from arcsine transformed data. to the spores (Fig. 2). At higher concentrations of zosteric acid ( 1 to $2 \%, \mathrm{wt} / \mathrm{vol}$ ), germination was inhibited but both adhesion to polystyrene and full germination were restored when $M$. grisea spores were washed with water (this experiment could not be conducted with $C$. lindemuthianum because the adhesive spore coat is readily removed by washing). During the washing treatment, it was observed that $M$. grisea spores in free solution did not clump or aggregate.

Vegetative growth of both species in liquid culture was unaffected at $0.1 \%(\mathrm{wt} / \mathrm{vol})$ zosteric acid, but whereas $C$. lindemuthianum was unaffected by concentrations of zosteric acid as high as $1 \%$ (wt/vol) (Table 1), M. grisea was more sensitive. Fungi alter the $\mathrm{pH}$ of their environment and the sulfo-oxy group of zosteric acid is know to be acid-labile below pH 5.5. However, the $\mathrm{pH}$ of the cultures containing zosteric acid were between 6.2 to 7.0 at the end of the experiment, suggesting that the effects observed were not artifacts of zosteric acid hydrolysis.

Although polystyrene is a good model surface for fungal spore adhesion, a more realistic, although less tractable, surface for adhesion studies is the plant leaf surface. Zosteric acid effectively inhibited attachment of spores of both fungi to the relevant leaf surface at concentrations down to $0.1 \%$ (wt/vol) (Fig. 3), although the inhibitory effect at low concentration on this more complex surface, compared with polystyrene, is less pronounced for $M$. grisea.

The effects of zosteric acid on germination and the development of postgermination infection structures of both species were examined on polystyrene and on the appropriate host leaf surface. Spores of $M$. grisea exposed to $0.1 \%$ (wt/vol) zosteric acid still germinated (Figs. 2 and 4A), although more slowly than controls (Fig. 4D), and the germ tubes were often misshapen (Fig. 4B). Polystyrene was a very effective inductive surface for appressoria formation in $M$. grisea, with approximately $80 \%$ of adhered, germinated spores forming mature, melanized appressoria at the end of short germ tubes within $10 \mathrm{~h}$ (Figs. 2 and 4E and F). In the presence of $0.1 \%(\mathrm{wt} / \mathrm{vol})$ zosteric acid, very few mature, melanized appressoria were formed although some immature appressoria were detectable at the ends of long germ tubes (Fig. 4C).

Appressorial induction in $C$. lindemuthianum was more easily evaluated on bean leaf surfaces than on polystyrene. Germination of the small percentage of adhered spores of $C$. lindemuthianum

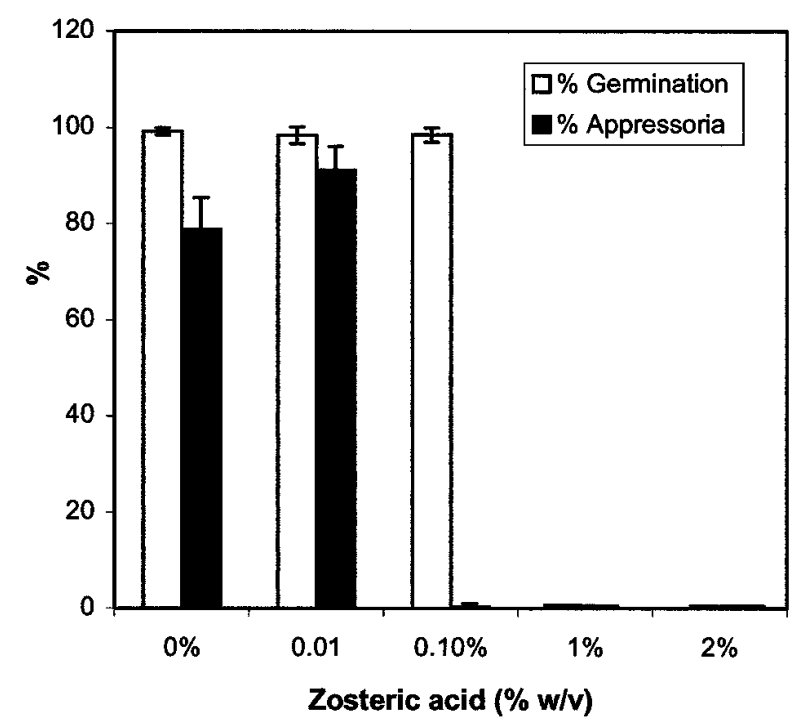

Fig. 2. Germination and appressorial formation on polystyrene of spores of Magnaporthe grisea in the presence of zosteric acid. Germination values refer to the percentage of attached spores that formed a recognizable germ tube. Appressorium formation is measured as the percentage of germinated spores that formed appressoria. All values $\pm 95 \%$ confidence limits were plotted from arcsine transformed data. 
was unaffected by $0.1 \%$ (wt/vol) zosteric acid, although higher concentrations did have some effect, with $1 \%$ (wt/vol) zosteric acid reducing germination to $45 \%$ of adhered spores (Fig. 5). Of the few attached spores that germinated in the presence of zosteric acid, only a very small percent $(<5 \%)$ went on to form appressoria, and less than $2 \%$ of appressoria penetrated leaf cells to form infection vesicles (Fig. 5). In the absence of zosteric acid, the majority of germinated spores formed appressoria and about $25 \%$ of appressoria formed detectable infection vesicles in host cells (Fig. 5). Coumaric acid had no effect on spore germination but appressorium formation was strongly inhibited. However, this effect of coumaric acid was qualitatively different from the effect of zosteric acid. In the presence of coumaric acid, germinated spores formed extensive mycelial growth that may have been due to phytotoxic effects of coumaric acid (observed in other experiments), causing nutrient leakage from the plant cells thus stimulating massive vegetative growth.

The ability of zosteric acid to protect rice plants against infection was tested in two types of plant inoculation. In the leaf droplet method, which is widely used for screening pathogen strains of pathogen and potential antifungal agents, control inoculations produced the standard brown necrotic lesions with grayish centers (Fig. 6A). Inoculations in the presence of zosteric acid at $\geq 0.2 \%$ (wt/vol) provided complete protection, with only the dried

TABLE 1. Effects of zosteric acid on mycelial growth of Colletotrichum lindemuthianum and Magnaporthe grisea

\begin{tabular}{lccc}
\hline \% Zosteric acid & Dry weight $(\mathrm{mg})^{\mathrm{a}}$ & $\mathrm{SE}^{\mathrm{b}}$ & $\mathrm{pH}^{\mathrm{c}}$ \\
\hline C. lindemuthianum & & & \\
0 & 68.8 & 7.6 & 7.14 \\
0.1 & 60.4 & 3.1 & 6.86 \\
1.0 & 60.3 & 2.5 & 6.88 \\
2.0 & $38.0^{*}$ & 2.5 & 6.95 \\
M. grisea & & & \\
0 & 184.7 & 20.0 & 5.9 \\
0.1 & 169.3 & 31.4 & 6.2 \\
1.0 & $63.3^{*}$ & 9.6 & 6.4 \\
2.0 & $52.0^{*}$ & 8.0 & 6.5 \\
\hline
\end{tabular}

${ }^{a}$ Asterisks denote values significantly different to control ( $0 \%$ zosteric acid) values for each fungus at $P=0.05$.

b Standard error.

${ }^{\mathrm{c}}$ Finishing $\mathrm{pH}$ of cultures.

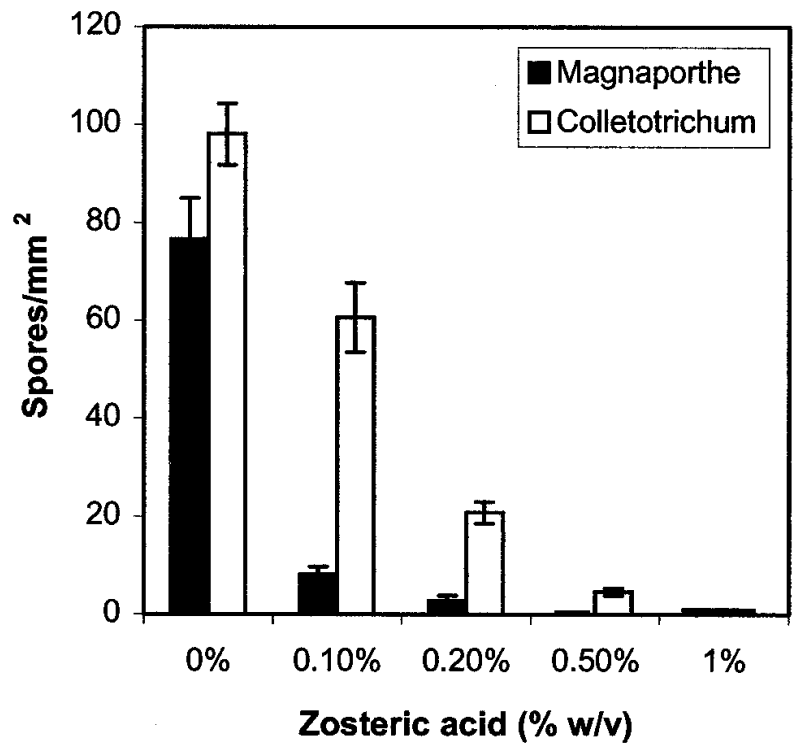

Fig. 3. Effect of zosteric acid on adhesion of spores of Colletotrichum lindemuthianum and Magnaporthe grisea to their respective host leaf surfaces. All values $\pm 95 \%$ confidence limits. white zosteric acid deposits evident at inoculation sites. Microscopical examination of the surface of the inoculated rice leaves showed typical melanized appressoria in control treatments, with the spores themselves becoming hyaline and difficult to image (Fig. 6B). In the presence of $0.2 \%$ (wt/vol) zosteric acid, spores present on the leaf surface had not germinated and retained their stainable contents (Fig. 6C).

In the second protection assay, glasshouse-grown rice plants were sprayed with zosteric acid and the leaves were allowed to dry overnight. Plants were sprayed with $M$. grisea spores, and lesion development was monitored. The results (Fig. 7) demonstrate reduced lesion development of zosteric acid-treated plants. Similar protection was obtained with bean leaves inoculated with C. lindemuthianum. Five days after inoculation, $11 \%$ of the area of inoculated control leaves showed chlorosis and early stages of necrosis characteristic of bean anthracnose symptoms, whereas plants presprayed with 0.1 and $1 \%$ (wt/vol) zosteric acid showed

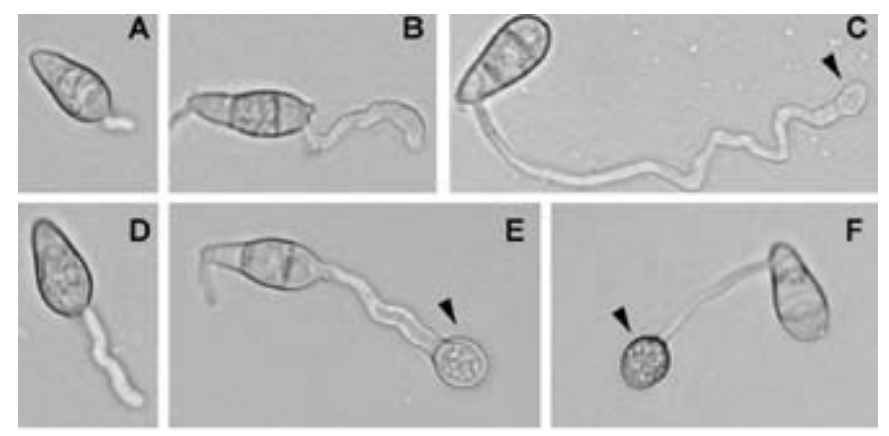

Fig. 4. Bright field micrographs illustrating the effects of zosteric acid on the induction of Magnaporthe grisea appressoria on polystyrene. Representative images of spores and appressoria (arrowed) are shown at $\mathbf{A}$ and $\mathbf{D}, 3 \mathrm{~h}, \mathbf{B}$ and $\mathbf{E}, 6 \mathrm{~h}$, and $\mathbf{C}$ and $\mathbf{F}, 10 \mathrm{~h}$ after application to polystyrene plates in the $\mathbf{A}$ to $\mathbf{C}$, presence or $\mathbf{D}$ to $\mathbf{F}$, absence of $0.1 \%$ zosteric acid. Magnification $\times 500$.

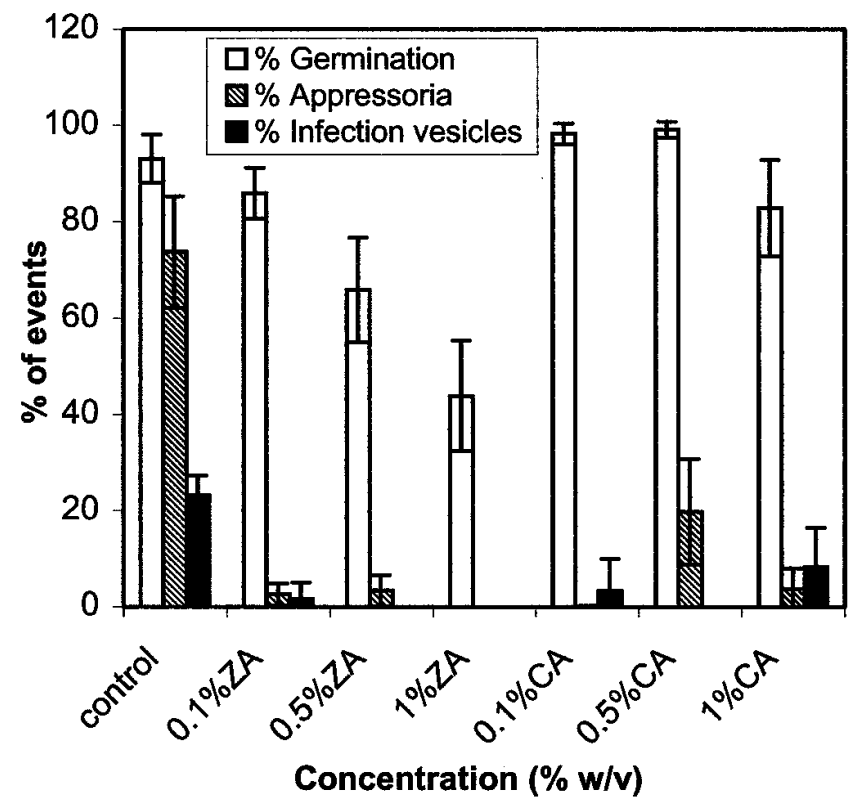

Fig. 5. Effects of zosteric acid (ZA) and p-coumaric acid (CA) on Colletotrichum lindemuthianum infection structure development on bean leaves. Germination values refer to the percentage of applied, attached spores that formed a recognizable germ tube. Appressorium formation is measured as the percentage of germinated spores that formed appressoria. Infection vesicle values refer to the percentage of spores that formed appressoria that went on to form primary infection vesicles in host epidermal cells. All values $\pm 95 \%$ confidence limits were plotted from arcsine transformed data. 
only mild chlorotic symptoms on less than $1 \%$ of the inoculated leaf area.

\section{DISCUSSION}

The objective of this study was to explore the potential in crop protection for compounds that target the spore adhesion phase of the plant-fungus interaction. The anti-adhesin chosen was zosteric acid, a natural sulfoxy phenolic acid that inhibits adhesion of barnacles, marine bacteria, and algal spores $(2,19)$. To explore effects on fungal spore adhesion, we initially used a model surface. Conidia of both test fungi, $M$. grisea and $C$. lindemuthianum, will attach to glass surfaces, but adhesion of $M$. grisea spores in particular, is stronger on hard, hydrophobic surfaces $(7,10)$. There-
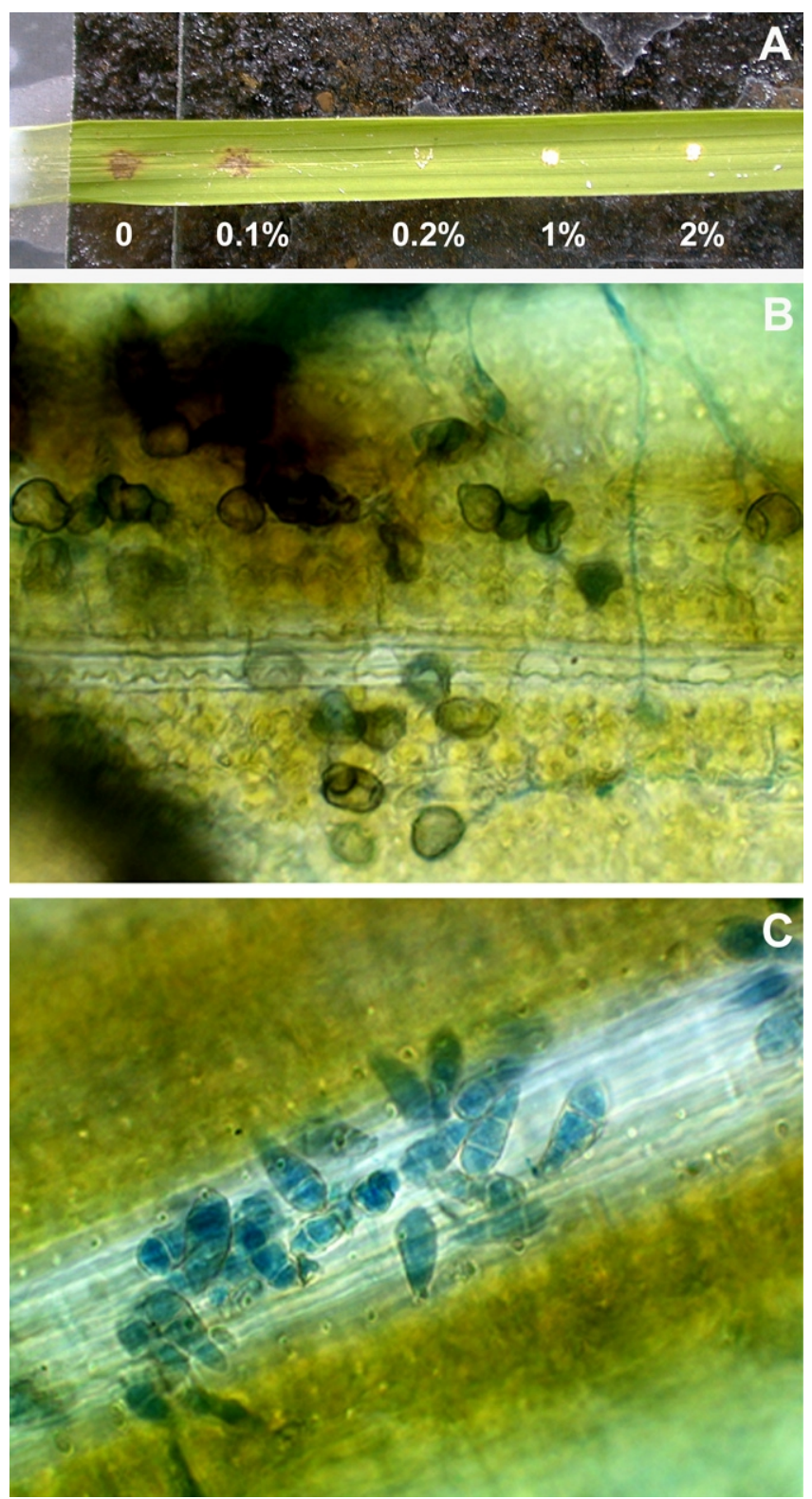

Fig. 6. Effect of zosteric acid on lesion and infection structure development on rice leaves following droplet inoculations with spores of Magnaporthe grisea. A, Macroscopic lesion development with zosteric acid at $\geq 0.2 \%$, providing complete protection, with only the dried white zosteric acid deposits evident at inoculation sites. Lesions from control (0\%) and $0.2 \%$ zosteric acid treatments were examined by bright-field microscopy after clearing and staining. B, In the control, dark, melanized appressoria are evident; the original spores, having lost their contents, are undetectable. C, The $0.2 \%$ zosteric acid treatment inhibited germination of the spores, which retained their stainable contents. Magnification $\times 500$. fore, as a model substrate, we used polystyrene petri dishes. The adhesion assay compares the density of spores, deposited from a droplet of spore suspension on the surface of a polystyrene plate, before and after the application of a washing treatment (10). This distinguishes spores that are merely resting on the dish surface from those that are truly adhered. In this assay, zosteric acid inhibited adhesion of spores of both fungi at concentrations as low as $0.01 \%(\mathrm{wt} / \mathrm{vol})$ although complete inhibition required much higher concentrations. Phenolic acids have antimicrobial action (4) but the effect of zosteric acid in inhibiting fungal spore adhesion appears to be a specific function of the sulfo-oxy group rather than a nonspecific phenolic effect because the equivalent, nonsulfoxy phenolic acid, $p$-coumaric acid did not inhibit spore adhesion to polystyrene at the concentrations tested. This observation lends further support to the previous conclusions $(2,19)$ that the phenyl sulfo-oxy ester is key in blocking adhesion.

Although polystyrene is a good model surface for fungal spore adhesion, a more realistic although considerably less tractable surface for adhesion studies is the plant leaf surface. Whereas in principle it would be preferential to apply the same procedure used in the polystyrene dish assay, in which spore counts are taken before and after washing, this is not practicable because of the more complex surface presented by the leaf, which physically retains spores even though they are not truly adhered. The rice leaf surface is a particularly difficult substrate to measure adhesion, being extremely hydrophobic and with a complex microtopography (17). Therefore, a different procedure was developed based on more dilute spore suspensions and a more rigorous washing regime incorporating Tween 80 to remove the unattached spores. The results of assays using this method were broadly consistent with those obtained from the model substrate, but adhesion of $C$. lindemuthianum spores in particular was less sensitive in the leaf assay to the lower concentrations of zosteric acid tested.

Adhesion plays at least three critical and well-established roles in the preinfection development of $M$. grisea: in the initial, rapid attachment of spores via spore tip mucilage; in the perception, surface signals leading to appressorial induction; and in the strong, adhesion of appressoria to the leaf cuticle to provide a resistance to the turgor pressure-driven leaf cell penetration mechanism. The evidence presented here shows that zosteric acid influences at least the first two of these stages: initial spore adhe-

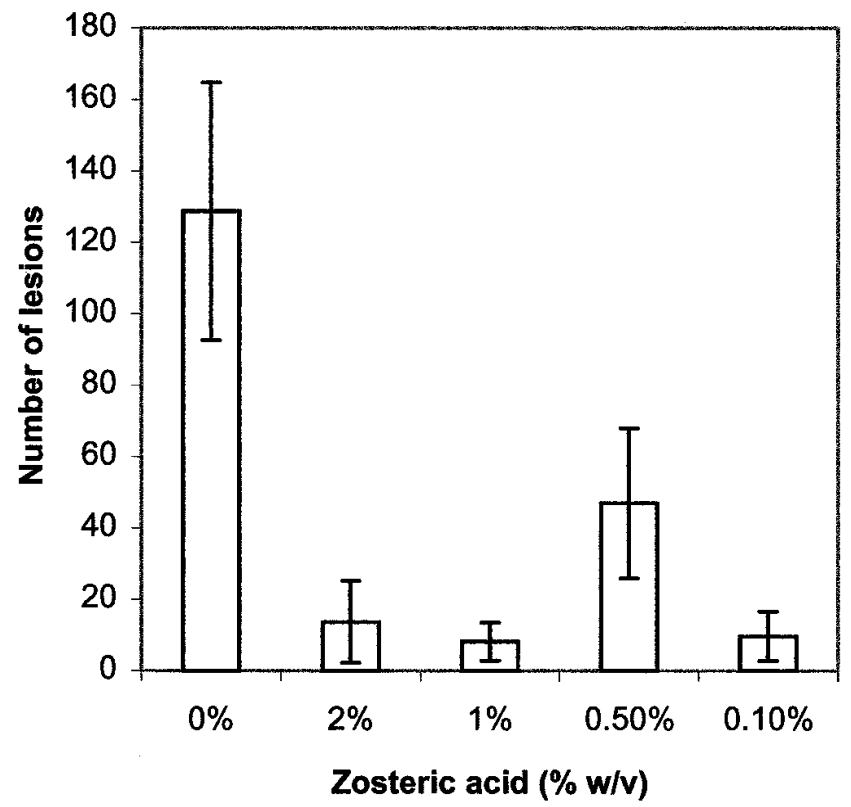

Fig. 7. Effect of zosteric acid on lesion development on rice leaves 3 days after inoculation with spores of Magnaporthe grisea. All values $\pm 95 \%$ confidence limits were plotted from arcsine transformed data. 
sion and appressorial induction. The ability of sulfated or sulfonated polymers to deter adhesion of microorganisms has been recognized for many years and has been utilized in a number of industrial applications, particularly in antifouling membrane technology (6). It is believed that the basis of this effect lies in the high affinity for water shown by sulfate or sulfonate groups that can increases the hydrophilicity (wettability) of the surface. It is possible that the inhibitory effect of zosteric acid on fungal spore adhesion manifests itself in a similar manner. Zosteric acid could complex with the spore adhesive, reducing its functionality, for example, by preventing or reducing the exclusion of water molecules from the adhesive-substratum interface. Alternatively, adsorption of zosteric acid to hydrophobic surfaces presented by polystyrene or a leaf cuticle could increase surface hydrophilicity, reducing the ability of the discharged adhesive to bond. Another possibility is that zosteric acid is acting as a direct competitor for functional groups such as adhesive domains within the adhesive.

We also demonstrate that even if spores attach to leaf surfaces, their subsequent development (but not their germination) is influenced by zosteric acid. Evidence is accumulating to show that pathogenic fungi perceive multiple cues presented by the surfaces of their hosts, using these to influence the development of infection structures (8, review). The perception of surface cues to trigger directional germ tube growth and appressorial differentiation may depend on a close association between cell and substrate, and this could also be influenced by adhesion molecules. For example, hydrophobins are small secreted proteins with the ability to self-assemble into amphipathic protein monolayers at solidliquid and liquid-air interfaces. $M$. grisea hydrophobins are encoded by the MPG1 gene (13), mutations which greatly reduce the ability to make appressoria. It has been speculated $(13,17)$ that the hydrophobins may self-assemble at the hydrophobic surface of the rice leaf, acting as adhesion proteins, providing a close association that could be an important signal in appressorial morphogenesis. Zosteric acid could interfere with surface interactions involving hydrophobins, thus preventing the appropriate signal transmission from occurring. Consistent with this is our observation that germ tubes and the extensive hyphae formed from spores of $M$. grisea in the presence of zosteric acid were not appressed closely to the polystyrene surface. Further experiments are underway to examine the possible direct interactions between zosteric acid and hydrophobin proteins.

The results presented here demonstrate that in controlled laboratory and glasshouse experiments, concentrations of zosteric acid that are not directly toxic to the fungi, reduce spore adhesion to leaf surfaces and influence the initiation of infection structures. Consequently, disease symptom development is reduced. The results suggest considerable potential for environmentally benign strategies for the control of plant disease based on anti-adhesion compounds. It may be argued that because the anti-adhesion agent does not directly kill the spores, and washing can reverse inhibition of adhesion, such protection may be transitory under field conditions. However, reduced adhesion may lower inoculum potential either because nonadhered spores are more easily detached by air movements or water splash or, as in the case of $M$. grisea, they rapidly lose viability (17). To translate this potential to practical field control requires further work on compounds of similar mode of action, with a higher specific activity, together with appropriate formulation to create a persistent anti-adhesion efficacy at the leaf surface. The development of such compounds is currently ongoing.

\section{ACKNOWLEDGMENTS}

Research was supported by PhycoGen, Inc., Falmouth, ME. We thank M. T. Jackson (International Rice Research Institute) for seeds of rice cv. CO 39, N. J. Talbot (University of Exeter) for cultures of Magnaporthe grisea, J. R. Green (University of Birmingham) for cultures of Colletotrichum lindemuthianum, R. O'Connell (IACR, Long Ashton) for seeds of Phaseolus vulgaris cv. Kievitsboon Koekoek, and A. Jennings for developing algorithms for spore counting by image analysis.

\section{LITERATURE CITED}

1. Braun, E. J., and Howard, R. J. 1994. Adhesion of fungal spores and germlings to host plant surfaces. Protoplasma 181:202-212.

2. Callow, M. E., and Callow, J. A. 1998. Attachment of zoospores of the fouling alga Enteromorpha in the presence of zosteric acid. Biofouling 13:87-95.

3. Deising, H., Nicholson, R. L., Haug, M., Howard, R. J., and Mendgen, K. 1992. Adhesion pad formation and the involvement of cutinase and esterases in the attachment of uredospores to the host cuticle. Plant Cell 4:1101-1111.

4. Denyer, S. P., and Hugo, W. B. 1991. Mechanisms of Action of Chemical Biocides: Their Study and Exploitation. Blackwell Scientific, Oxford.

5. Epstein, L., and Nicholson, R. L. 1997. Adhesion of spores and hyphae to plant surfaces. Pages 11-25 in: The Mycota, Vol. 5. G. Carroll and P. Tudsynski, eds. Springer-Verlag, Berlin, Germany.

6. Gregor, H. P., and Gregor, C. D. 1978. Synthetic membrane technology. Sci. Am. 239:88-101.

7. Hamer, J. E., Howard, R. J., Valent, B., and Chumley, F. G. 1998. A mechanism for surface attachment in spores of a plant pathogenic fungus. Science 239:288-290.

8. Heath, M. C. 2000. The first touch. Physiol. Mol. Plant Pathol. 56:49-50.

9. Howard, R. J., and Ferrari, M. A. 1989. Role of melanin in appressorium function. Exp. Mycol. 13:403-418.

10. Hughes, H. B., Carzaniga, R., Rawlings, S. L., Green, J. R., and O'Connell, R. J. 1999. Spore surface glycoproteins of Colletotrichum lindemuthianum are recognised by a monoclonal antibody which inhibits adhesion to polystyrene. Microbiology 145:1927-1936.

11. Inoue, S., Kato, T., and Jordan, V. W. L. 1987. Inhibition of appressorial adhesion of Pyricularia oryzae to barley leaves by fungicides. Pest. Sci. 19:145-152.

12. Jones, M. J., and Epstein, L. 1989. Adhesion of Nectria haematococca macroconidia. Physiol. Mol. Plant Pathol. 20:47-60.

13. Kershaw, M. J., and Talbot, N. J. 1998. Hydrophobins and repellents: Proteins with fundamental roles in fungal morphogenesis. Fungal Genet. Biol. 23:18-33.

14. Mathur, R. S., Barnett, H. L., and Lilly, V. G. 1950. Sporulation of Colletotrichum lindemuthianum in culture. Phytopathology 40:104-114.

15. Nicholson, R. L., and Epstein, L. 1991. Adhesion of fungi to the plant surface: Prerequisite for pathogenesis. Pages 3-23 in: The Fungal Spore and Disease Initiation in Plants and Animals. H. Hoch and G. T. Cole, eds. Plenum Press, New York.

16. Pain, N. A., O'Connell, R. J., Bailey, J. A., and Green, J. R. 1992. Monoclonal antibodies which show restricted binding to four Colletotrichum species: C. lindemuthianum, C. malvarum, C. orbiculare, and $C$. trifolii. Physiol. Mol. Plant Pathol. 41:111-126.

17. Talbot, N. J. 1995. Having a blast: Exploring the pathogenicity of Magnaporthe grisea. Trends Microbiol. 3:9-16.

18. Talbot, N. J., Ebbole, D. J., and Hamer, J. E. 1993. Identification and characterization of MPG1, a gene involved in pathogenicity from the rice blast fungus Magnaporthe grisea. Plant Cell 5:1575-1590.

19. Todd, J. S., Zimmerman, R. C., Crews, P., and Alberte, R. S. 1993. The antifouling activity of natural and synthetic phenolic acid sulphate esters. Phytochemistry 34:401-404. 